\title{
Pulmonary vascular response patterns during exercise in interstitial lung disease
}

\author{
Luiza H. Degani-Costa ${ }^{1,2}$, Barbara Levarge ${ }^{2}$, Subba R. Digumarthy ${ }^{3}$, \\ Aaron S. Eisman ${ }^{4}$, R. Scott Harris ${ }^{2}$ and Gregory D. Lewis ${ }^{2,4}$
}

Affiliations: ${ }^{1}$ Respiratory Division, Paulista School of Medicine, Federal University of São Paulo, São Paulo, Brazil. ${ }^{2}$ Pulmonary and Critical Care Unit, Massachusetts General Hospital/Harvard Medical School, Boston, MA, USA. ${ }^{3}$ Thoracic Imaging and Intervention Division, Massachusetts General Hospital/Harvard Medical School, Boston, MA, USA. ${ }^{4}$ Cardiology Division, Massachusetts General Hospital/Harvard Medical School, Boston, MA, USA.

Correspondence: Gregory D. Lewis, Cardiac Unit Associates, 55 Fruit Street, Boston, MA 02114-2696, USA. E-mail: glewisapartners.org

ABSTRACT When overt pulmonary hypertension arises in interstitial lung disease (ILD), it contributes to exercise intolerance. We sought to determine the functional significance of abnormal pulmonary arterial pressure (PAP) responses to exercise in ILD.

27 ILD patients and 11 age-matched controls underwent invasive cardiopulmonary exercise testing (iCPET). Mean PAP (mPAP) was indexed to cardiac output $\left(Q^{\prime} T\right)$ during exercise, with a mPAP- $Q^{\prime} \mathrm{T}$ slope $\geqslant 3 \mathrm{mmHg} \cdot \mathrm{min} \cdot \mathrm{L}^{-1}$ defined as an abnormal pulmonary vascular response.

All control subjects had $\mathrm{mPAP}-\mathrm{Q}^{\prime} \mathrm{T}$ slopes $<3 \mathrm{mmHg} \cdot \mathrm{min} \cdot \mathrm{L}^{-1}\left(\right.$ mean $\left.\pm \mathrm{SEM} 1.5 \pm 0.1 \mathrm{mmHg} \cdot \mathrm{min} \cdot \mathrm{L}^{-1}\right)$. 15 ILD patients had $\mathrm{mPAP}-\mathrm{Q}^{\prime} \mathrm{T}$ slopes $\geqslant 3 \mathrm{mmHg} \cdot \mathrm{min} \cdot \mathrm{L}^{-1}\left(4.1 \pm 0.2 \mathrm{mmHg} \cdot \mathrm{min} \cdot \mathrm{L}^{-1}\right)$ and were labelled as having ILD plus pulmonary vascular dysfunction (PVD). Subjects without pulmonary hypertension and with $\mathrm{mPAP}-\mathrm{Q}^{\prime} \mathrm{T}$ slopes $<3 \mathrm{mmHg} \cdot \mathrm{min} \cdot \mathrm{L}^{-1}\left(1.9 \pm 0.2 \mathrm{mmHg} \cdot \mathrm{min} \cdot \mathrm{L}^{-1}\right)$ were labelled as ILD minus PVD $(n=12)$. ILD+PVD and ILD-PVD patients did not differ in terms of age, sex, body mass index, pulmonary function testing or degree of exercise oxygen desaturation. Peak oxygen consumption was lower in ILD+PVD than in ILD-PVD $\left(13.0 \pm 0.9\right.$ versus $\left.17 \pm 1.1 \mathrm{~mL} \cdot \mathrm{kg}^{-1} \cdot \mathrm{min}^{-1}, \mathrm{p}=0.012\right)$ and controls $\left(19.8 \pm 1.7 \mathrm{~mL} \cdot \mathrm{kg}^{-1} \cdot \mathrm{min}^{-1}, \mathrm{p}=0.003\right)$. ILD+PVD patients had increased dead space volume $(V \mathrm{D}) /$ tidal volume $(V \mathrm{~T})$ and minute ventilation/carbon dioxide production at the anaerobic threshold.

In ILD, mPAP-Q'T slope $\geqslant 3 \mathrm{mmHg} \cdot \mathrm{min} \cdot \mathrm{L}^{-1}$ is associated with lower peak oxygen consumption, increased $V \mathrm{D} / V \mathrm{~T}$ and inefficient ventilation. While noninvasive parameters were unable to predict those with abnormal pulmonary vascular responses to exercise, $\mathrm{iCPET}$-derived $\mathrm{mPAP}-\mathrm{Q}^{\prime} \mathrm{T}$ slope may aid in identifying physiologically significant, early pulmonary vascular disease in ILD.

@ERSpublications

PAP responses to exercise may help to refine resting phenotypes related to pulmonary vascular dysfunction in ILD http://ow.ly/M0nMa

Editorial comment in: Eur Respir J 2015; 46: 583-586 [DOI: 10.1183/09031936.00061015]

Received: Oct 142014 | Accepted after revision: April 062015 | First published online: May 142015

Support statement: This work was supported by the Hassenfeld Clinical Scholar Award (G.D. Lewis) and National Heart, Lung, and Blood Institute grant R01HL119154 (G.D. Lewis). Funding information for this article has been deposited with FundRef.

Conflict of interest: None declared.

Copyright OERS 2015 


\section{Introduction}

Pulmonary hypertension is common in the setting of interstitial lung disease (ILD) and may contribute to exercise intolerance in this patient population [1]. Currently, the diagnosis of pulmonary hypertension is based only on pulmonary haemodynamics measured at rest, leaving patients with abnormal pulmonary vascular response patterns during exercise unrecognised.

There has been renewed interest in the study of pulmonary vascular responses to exercise and a definition of exercise-induced pulmonary hypertension (Ei-PH) based on the pulmonary arterial pressure (PAP)cardiac output $\left(Q^{\prime} \mathrm{T}\right)$ relationship has been suggested to reflect pulmonary vascular disease better than using an absolute cut-off value of mean PAP (mPAP) at peak exercise [2, 3]. A mPAP-Q'T slope $\geqslant 3 \mathrm{mmHg} \cdot \mathrm{min} \cdot \mathrm{L}^{-1}$ during maximum incremental exercise indicates an abnormal pulmonary vascular response in patients with our without pulmonary hypertension at rest.

The presence of a pulmonary hypertensive response during exercise has been repeatedly associated with reduced exercise capacity in heart failure, pulmonary arterial hypertension (PAH) and valvular disease [4-6]. Moreover, it has been shown to negatively impact survival in patients with heart failure with reduced left ventricular ejection fraction (LVEF) [4] as well as in aortic stenosis [7]. Ei-PH has also been considered a risk factor for developing resting pulmonary hypertension both in chronic obstructive pulmonary disease (COPD) [8] and scleroderma patients [9].

Overt, resting pulmonary hypertension is known to complicate the course of ILD, being associated with poorer functional status and worsened outcomes [10-15], but the clinical significance of abnormal pulmonary vascular responses to exercise in ILD has not been characterised. In this study, we used invasive cardiopulmonary exercise testing (iCPET) to test the hypothesis that abnormal pulmonary vascular responses to exercise (i.e. $\mathrm{mPAP}-\mathrm{Q}^{\prime} \mathrm{T}$ slope $\geqslant 3 \mathrm{mmHg} \cdot \mathrm{min} \cdot \mathrm{L}^{-1}$ ) would negatively impact functional capacity in ILD.

\section{Methods}

Study design

Among 536 patients who underwent iCPET between February 2006 and August 2013 at the Massachusetts General Hospital, Boston, MA, USA, we identified patients with proven ILD based on high-resolution computed tomography (HRCT) findings adjudicated by a thoracic radiologist and/or lung biopsy. Exclusion criteria consisted of: LVEF $<50 \%$; more than mild valvular heart disease; and lack of available chest computed tomography images or complete exercise haemodynamic measurements. Age- and sex-matched control subjects with normal aerobic capacity (peak oxygen consumption $\left(V^{\prime} \mathrm{O}_{2}\right) \geqslant 80 \%$ of the predicted value on the basis of age, sex and height) and without ILD, pulmonary hypertension or heart disease were selected from the same database. Demographic characteristics of the population, as well as smoking history, pulmonary function test (PFT) results (spirometry, lung volumes and diffusing capacity of the lung for carbon monoxide (DLCO)), arterial blood gas results, resting haemodynamic measurements and radiographic findings for each subject were recorded. Resting pulmonary haemodynamics were assessed by right heart catheterisation performed in the supine position immediately before iCPET. PFTs were performed within 3 months of iCPET. Similarly, radiographic findings (presence of ground-glass opacities, reticulation, traction bronchiectasis and honeycombing) were considered for further analysis only if HRCT imaging was available within 6 months of the iCPET. The study was approved by the Institutional Review Board of the Massachusetts General Hospital and complies with the Declaration of Helsinki.

\section{Cardiopulmonary exercise testing and invasive haemodynamic measurements}

The cardiopulmonary exercise testing (CPET) protocol and the methodology to perform invasive hemodynamic measurements during exercise have been previously published $[3,4]$. In summary, prior to iCPET, all subjects underwent placement of a pulmonary arterial catheter via the internal jugular vein and placement of a systemic arterial catheter via the radial artery. Patients and healthy controls underwent a maximal incremental-ramp upright exercise test on an electromagnetically braked cycle-ergometer (5$20-\mathrm{W} \cdot \mathrm{min}^{-1}$ continuous ramp after an initial 2-3-min period of unloaded pedalling; MedGraphics, St Paul, MN, USA) with simultaneous haemodynamic monitoring (Witt Biomedical Inc., Melbourne, FL, USA). mPAP, pulmonary capillary wedge pressure (PCWP), and mean radial arterial pressure were measured in the upright position, and averaged over the respiratory cycle while patients were seated on the bike, at rest and at 1-min intervals during exercise. Simultaneous measurement of arterial and mixed venous oxygen content allowed calculation of arteriovenous oxygen content difference $\left(\mathrm{Ca}-\mathrm{vO}_{2}\right)$ and, consequently, the minute-by-minute Fick $Q^{\prime} \mathrm{T}\left(V^{\prime} \mathrm{O}_{2}=Q^{\prime} \mathrm{T} \times C \mathrm{a}-\mathrm{vO}_{2}\right)$. In one subject, we used simultaneously measured ventriculographic $Q^{\prime} \mathrm{T}$ (i.e. left ventricular end-diastolic volume multiplied by LVEF at rest and at peak exercise) to derive mPAP-Q'T slope because supplemental oxygen precluded Fick $Q^{\prime} \mathrm{T}$ measurements. 
Definition of haemodynamic groups

Pulmonary hypertension at rest was defined according to current guidelines as mPAP $\geqslant 25 \mathrm{mmHg}$ [16]. During exercise, we assessed the relationship between $\mathrm{mPAP}$ and $\mathrm{Q}^{\prime} \mathrm{T}$ augmentation. A slope of a linear regression between $\mathrm{mPAP}$ and $\mathrm{Q}^{\prime} \mathrm{T} \geqslant 3 \mathrm{mmHg} \cdot \mathrm{min} \cdot \mathrm{L}^{-1}$ or pulmonary vascular resistance $(\mathrm{PVR}) \geqslant 3 \mathrm{Wood}$ units at peak exercise defined an abnormal pulmonary vascular response to exercise $[2,3]$. Patients were said to have normal pulmonary haemodynamics if they presented with $\mathrm{mPAP}<25 \mathrm{mmHg}$ at rest and showed $\mathrm{mPAP}-\mathrm{Q}^{\prime} \mathrm{T}$ slope $<3 \mathrm{mmHg} \cdot \mathrm{min} \cdot \mathrm{L}^{-1}$ and $\mathrm{PVR}<3$ Wood units at peak exercise.

\section{Statistical analysis}

Continuous quantitative variables were tested for normality and considered to have a normal distribution, being presented as mean \pm SEM. The independent-samples Student's t-test was used for comparison of parametric data between groups. Pearson's correlation was performed when investigating the relationship between normally distributed variables. Categorical data are presented as frequencies or percentages and the Chi-squared test was used for comparisons when appropriate. Linear regression analysis was used to determine $\mathrm{mPAP}-\mathrm{Q}^{\prime} \mathrm{T}$ slopes and logistic regression was applied to investigate if noninvasive parameters of the CPET were able to predict an abnormal pulmonary vascular response to exercise. Multiple-subject $\mathrm{mPAP}-Q^{\prime} \mathrm{T}$ data were pooled for linearity analysis according to the method of Poon [17]. The statistical analysis was performed using SPSS version 20 (SPSS Inc., Chicago, IL, USA) and a p-value $<0.05$ was considered statistically significant.

\section{Results}

\section{Study population}

27 patients with ILD and 11 controls met the study's inclusion criteria, and their baseline characteristics are reported in table 1. Referral for iCPET was uniformly to evaluate dyspnoea on exertion. Clinical diagnoses were taken from medical records and reflect the attending physician's opinion on the cases.

TABLE 1 Demographics, pulmonary function and blood gas analysis

\begin{tabular}{|c|c|c|c|}
\hline & ILD & Controls & p-value \\
\hline Subjects $\mathrm{n}$ & 27 & 11 & \\
\hline Age years & $65.2 \pm 2.4$ & $61.5 \pm 2.0$ & 0.258 \\
\hline Female \% & 52 & 54 & 0.972 \\
\hline Caucasian \% & 96 & 100 & 1.000 \\
\hline Positive smoking history \% & 59 & 55 & 0.534 \\
\hline Smoking history pack-years & $35.1 \pm 11.4$ & $25.8 \pm 13.6$ & 0.612 \\
\hline BMI $\mathrm{kg} \cdot \mathrm{m}^{-2}$ & $27.8 \pm 1.1$ & $30.0 \pm 1.3$ & 0.081 \\
\hline \multicolumn{4}{|l|}{ Radiographic pattern of ILD $n$} \\
\hline UIP & 18 & & \\
\hline NSIP & 3 & & \\
\hline $\mathrm{OP}$ & 2 & & \\
\hline Smoking-related fibrosis & 1 & & \\
\hline Lymphocytic interstitial pneumonia & 1 & & \\
\hline Radiation-induced fibrosis & 1 & & \\
\hline Sarcoidosis & 1 & & \\
\hline FEV $1 \%$ predicted & $69 \pm 3$ & $102 \pm 5$ & $<0.001$ \\
\hline FVC $\%$ predicted & $68 \pm 3$ & $105 \pm 5$ & $<0.001$ \\
\hline FEV $1 / F V C \%$ predicted & $103 \pm 2$ & $98 \pm 2$ & 0.055 \\
\hline RV \% predicted & $66 \pm 4$ & $92 \pm 6$ & 0.004 \\
\hline TLC \% predicted & $69 \pm 3$ & $102 \pm 3$ & $<0.001$ \\
\hline RV/TLC \% predicted & $99 \pm 4$ & $89 \pm 6$ & 0.213 \\
\hline DLCO & $45 \pm 4$ & $94 \pm 6$ & $<0.001$ \\
\hline $\mathrm{Hb} \mathbf{g} \cdot \mathbf{d L}^{-1}$ & $12.8 \pm 0.3$ & $13.5 \pm 0.3$ & 0.118 \\
\hline $\mathrm{PaO}_{2} \mathrm{mmHg}$ & $82 \pm 3$ & $101 \pm 4$ & $<0.001$ \\
\hline $\mathrm{SO}_{2} \%$ & $96.0 \pm 0.4$ & $97.6 \pm 0.2$ & 0.013 \\
\hline
\end{tabular}

Data are presented as mean \pm SEM unless otherwise stated. ILD: interstitial lung disease; BMI: body mass index; UIP: usual interstitial pneumonia; NSIP: nonspecific interstitial pneumonia; OP: organising pneumonia; FEV1: forced expiratory volume in $1 \mathrm{~s}$; FVC: forced vital capacity; RV: residual volume; TLC: total lung capacity; $D \mathrm{LCO}_{\mathrm{Hb}}$ : diffusing capacity of the lung for carbon monoxide corrected for haemoglobin; $\mathrm{Hb}$ : haemoglobin; $\mathrm{PaO}_{2}$ : arterial oxygen tension; $\mathrm{SO}_{2}$ : oxygen saturation. Bold indicates statistical significance. 
They included: idiopathic pulmonary fibrosis (IPF) ( $\mathrm{n}=12$; of whom, all were classified as having usual interstitial pneumonia (UIP) radiographically and eight out of eight patients with biopsies showed UIP); combined emphysema plus fibrosis ( $n=4$; of whom, two had UIP, one had smoking-related ILD and one had organising pneumonia radiographically); fibrosis due to connective tissue diseases (CTDs) (Sjögren syndrome, scleroderma or antisynthetase syndrome) ( $n=6$; of whom, one patient with Sjögren's had lymphocytic interstitial pneumonia, one scleroderma patient had organising pneumonia and one had UIP, one subject with CREST (calcinosis, Raynaud's phenomenon, oesophageal dysmotility, sclerodactyly and telangiectasia) syndrome had nonspecific interstitial pneumonia (NSIP) and one had UIP, and one patient with antisynthetase syndrome had NSIP); sarcoidosis ( $\mathrm{n}=1$; with biopsy-proven pulmonary sarcoidosis and a radiographic classification of pulmonary sarcoidosis); radiation-induced lung fibrosis ( $\mathrm{n}=1$; in whom, the radiographic diagnosis was radiation-induced ILD); and ILD of unknown aetiology ( $\mathrm{n}=3$; of whom, two had UIP and one had NSIP radiographically). In each of the 12 subjects who underwent lung biopsy, the anatomopathologic diagnosis with in agreement with the radiographic pattern, which, in turn, was highly consistent with the clinical diagnoses.

All control subjects were referred for iCPET for investigation of unexplained dyspnoea but were found to have normal physiological responses to maximum incremental exercise testing. Obesity $(n=7)$ was prevalent among controls and may have accounted for dyspnoea despite normal cardiorespiratory fitness in the setting of the high metabolic cost of performing work. Chart review also revealed the presence of other common conditions in individuals with an average age of 61 years: hypertension $(n=5)$, obstructive sleep apnoea $(n=4)$, hypothyroidism $(n=2)$, coronary artery disease with previous percutaneous coronary intervention $(n=2)$, previous deep vein thrombosis without pulmonary embolism $(n=1)$, asthma $(n=1)$ and fibromyalgia $(n=1)$.

Only one patient was on supplemental oxygen at the time of the test, which precluded the measurement of $V^{\prime} \mathrm{O}_{2}$.

\section{Haemodynamic profile at rest}

ILD subjects had, on average, higher mPAP and PVR at rest than controls $(\mathrm{p}<0.05)$ (table 2$)$. Seven $(24 \%)$ ILD patients had pulmonary hypertension at rest, five of whom were classified as having pre-capillary pulmonary hypertension (mPAP $\geqslant 25 \mathrm{mmHg}$ and mean PCWP (mPCWP) $\leqslant 15 \mathrm{mmHg}$ ) and two as post-capillary pulmonary hypertension ( $\mathrm{mPAP} \geqslant 25 \mathrm{mmHg}$ and $\mathrm{mPCWP}>15 \mathrm{mmHg}$ ). Despite the higher PVR and mPAP, resting stroke volume, $Q^{\prime} T$ and cardiac index were relatively preserved and close to those shown by controls.

\section{Exercise gas exchange and haemodynamics}

CPET parameters for both groups are presented in table 2. As expected, ILD subjects had worse aerobic capacity based on the $\%$ predicted peak $V^{\prime} \mathrm{O}_{2}$ and lower achieved workloads than controls $(\mathrm{p}<0.05)$. In addition, subjects with ILD had lower arterial oxygen tension $\left(\mathrm{PaO}_{2}\right)$, arterial oxygen content and oxygen saturation $\left(\mathrm{SO}_{2}\right)$ than did controls, both at rest and at peak exercise. Unlike the controls, dead space ventilation $\left(V^{\prime} \mathrm{D}\right) /$ tidal volume $(V \mathrm{~T})$ in ILD patients did not fall appropriately during exercise. No patient demonstrated a primary pulmonary mechanical limit to exercise (i.e. minute ventilation/maximum voluntary ventilation $>0.7$ at the anaerobic threshold). At peak exercise, ILD subjects had higher mPAP and PVR, and lower $Q^{\prime} T$ than controls $(\mathrm{p}<0.05)$.

\section{Patterns of pulmonary vascular response to exercise}

All control subjects showed a normal pulmonary vascular response to exercise, with $\mathrm{mPAP}-\mathrm{Q}^{\prime} \mathrm{T}$ slope being, on average, $1.5 \pm 0.1 \mathrm{mmHg} \cdot \mathrm{min} \cdot \mathrm{L}^{-1}$, while the mean group $\mathrm{mPAP}-\mathrm{Q}^{\prime} \mathrm{T}$ slope for ILD subjects was $3.1 \pm 0.3 \mathrm{mmHg} \cdot \mathrm{min} \cdot \mathrm{L}^{-1}$. Subjects with ILD due to CTD or sarcoidosis $(\mathrm{n}=7)$ showed similar $\mathrm{mPAP}-\mathrm{Q}^{\prime} \mathrm{T}$ slopes compared to subjects with other causes of ILD $\left(3.1 \pm 0.6\right.$ versus $2.8 \pm 0.3 \mathrm{mmHg} \cdot \mathrm{min} \cdot \mathrm{L}^{-1}$, respectively; $\mathrm{p}=0.62)$.

15 ILD patients had a mPAP-Q'T slope $\geqslant 3 \mathrm{mmHg} \cdot \mathrm{min} \cdot \mathrm{L}^{-1}$, and were classified as abnormal and labelled as having ILD plus pulmonary vascular dysfunction (PVD) $(n=15)$. Subjects who had no pulmonary hypertension at rest and showed a normal pulmonary vascular response to exercise composed the group ILD minus PVD ( $\mathrm{n}=12)$.

The ILD+PVD group had higher mPAP at rest and a much steeper slope during exercise $\left(4.1 \pm 0.2 \mathrm{mmHg} \cdot \mathrm{min} \cdot \mathrm{L}^{-1}\right)$ than did the ILD-PVD $\left(1.9 \pm 0.2 \mathrm{mmHg} \cdot \mathrm{min} \cdot \mathrm{L}^{-1}\right)$ and the control groups $\left(1.5 \pm 0.1 \mathrm{mmHg} \cdot \mathrm{min} \cdot \mathrm{L}^{-1}\right)(\mathrm{p}<0.001)$ (fig. 1). Poon adjustment yielded similar $\mathrm{mPAP}-\mathrm{Q}^{\prime} \mathrm{T}$ values in each group $\left(4 \pm 0.2,1.8 \pm 0.2\right.$ and $1.5 \pm 0.2 \mathrm{mmHg} \cdot \mathrm{min} \cdot \mathrm{L}^{-1}$, respectively) (fig. $1 \mathrm{a}$ and $\mathrm{b}$ ). Although the ILD-PVD group started exercise at higher levels of mPAP that controls, their slope was similar to that of the latter $(\mathrm{p}>0.05)$. 
TABLE 2 Haemodynamics, blood gas and cardiopulmonary exercise testing parameters at rest and at maximum exercise in interstitial lung disease (ILD) patients and controls

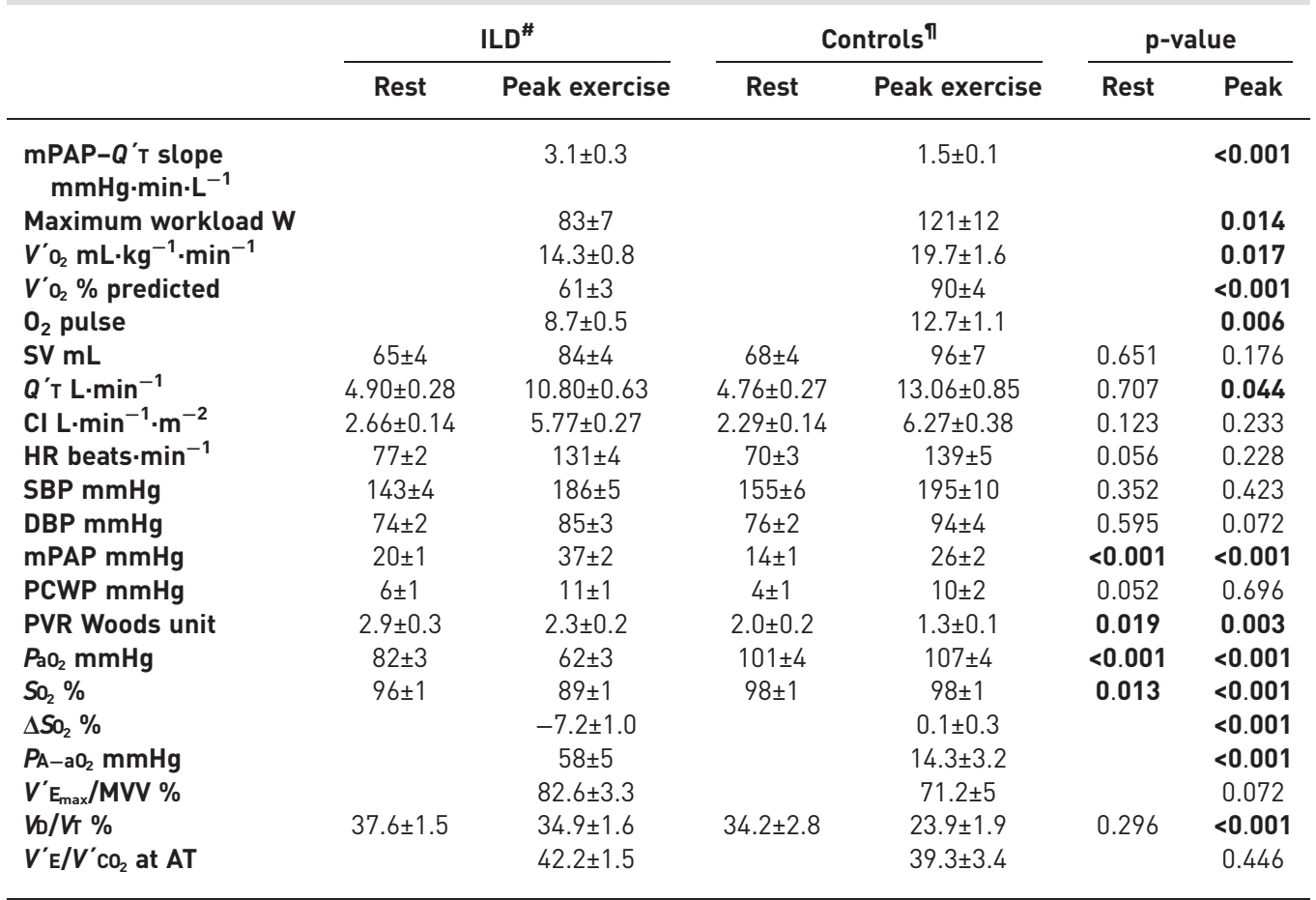

Data are presented as mean \pm SEM, unless otherwise stated. mPAP: mean pulmonary arterial pressure; $Q^{\prime} \mathrm{T}$ : cardiac output; $V^{\prime} \mathrm{O}_{2}$ : oxygen consumption; SV: stroke volume; QT: cardiac output; $\mathrm{Cl}$ : cardiac index; HR: heart rate; SBP: systolic blood pressure; DBP: diastolic blood pressure; PCWP: pulmonary capillary wedge pressure; PVR: pulmonary vascular resistance; $\mathrm{PaO}_{2}$ : arterial oxygen tension; $\mathrm{SO}_{2}$ : oxygen saturation; $\Delta$ : change in; $P_{\mathrm{A}-a O_{2}}$ : alveolar-arterial oxygen tension difference; $V^{\prime} \mathrm{E}_{\max }$ : maximum minute ventilation at peak exercise; MVV: maximum voluntary ventilation; $V_{D}$ : dead space volume; $V_{T}$ : tidal volume; $V^{\prime} E$ : minute ventilation; $V^{\prime} \mathrm{CO}_{2}$ : carbon dioxide production; $\mathrm{AT}$ : anaerobic threshold. ${ }^{\#}: \mathrm{n}=27 ;{ }^{\uparrow}: \mathrm{n}=11$. Bold indicates statistical significance.

When analysing the patterns of pulmonary vascular response to exercise in ILD+PVD, there were eight patients who developed abnormal pulmonary vascular responses to exercise without having pulmonary hypertension at rest. All patients with PVR at peak exercise $\geqslant 3$ Wood units also showed a mPAP- $Q^{\prime} T$ slope $\geqslant 3 \mathrm{mmHg} \cdot \mathrm{min} \cdot \mathrm{L}^{-1}$. However, it is interesting to note that five ILD subjects with $\mathrm{mPAP}-\mathrm{Q}^{\prime} \mathrm{T}$ slope $\geqslant 3 \mathrm{mmHg} \cdot \mathrm{min} \cdot \mathrm{L}^{-1}$ presented with $\mathrm{PVR}<3$ Wood units at peak exercise; therefore, peak PVR cannot be used as a single criterion to define abnormal pulmonary vascular response to exercise (fig. 2).

Using a cut-off value of $30 \mathrm{mmHg}$ for peak mPAP to define Ei-PH would have led to misclassification of $42 \%$ of the ILD-PVD subjects, who had normal pulmonary vascular responses to exercise but reached high levels of peak mPAP solely on account of the increased $Q^{\prime} T$ (fig. 3). A similar phenomenon was seen in the control group, as four of the 11 subjects achieved peak $\mathrm{mPAP} \geqslant 30 \mathrm{mmHg}$ despite having normal aerobic capacity and $\mathrm{mPAP}-\mathrm{Q}^{\prime} \mathrm{T}$ slope.

\section{ILD+PVD versus ILD-PVD comparison}

There were no differences in terms of age, sex, body mass index (BMI), PFT or radiographic findings between ILD+PVD and ILD-PVD subjects (table 3). The prevalence of smokers and ex-smokers tended to be higher in the ILD+PVD group, but this difference was not statistically significant $(p=0.096)$. The ILD $+\mathrm{PVD}$ group demonstrated higher mPAP $(22 \pm 1$ versus $16 \pm 1 \mathrm{mmHg}$ in ILD+PVD and ILD-PVD, respectively; $\mathrm{p}=0.001)$ and PCWP $(9 \pm 1$ versus $6 \pm 1 \mathrm{mmHg}$ in ILD+PVD and ILD-PVD, respectively; $\mathrm{p}=0.039$ ) at rest, but neither group was above the upper limit of the normal range. No differences were seen in $Q^{\prime} \mathrm{T}$, cardiac index, $\mathrm{PaO}_{2}$ or $\mathrm{SO}_{2}$ at rest.

Aerobic capacity was more markedly reduced in ILD+PVD subjects based on an earlier anaerobic threshold $\left(30 \pm 2 \%\right.$ versus $38 \pm 2 \%$ of predicted peak $\left.V^{\prime} \mathrm{O}_{2}, \mathrm{p}=0.025\right)$ and a mean peak $V^{\prime} \mathrm{O}_{2}$ of 

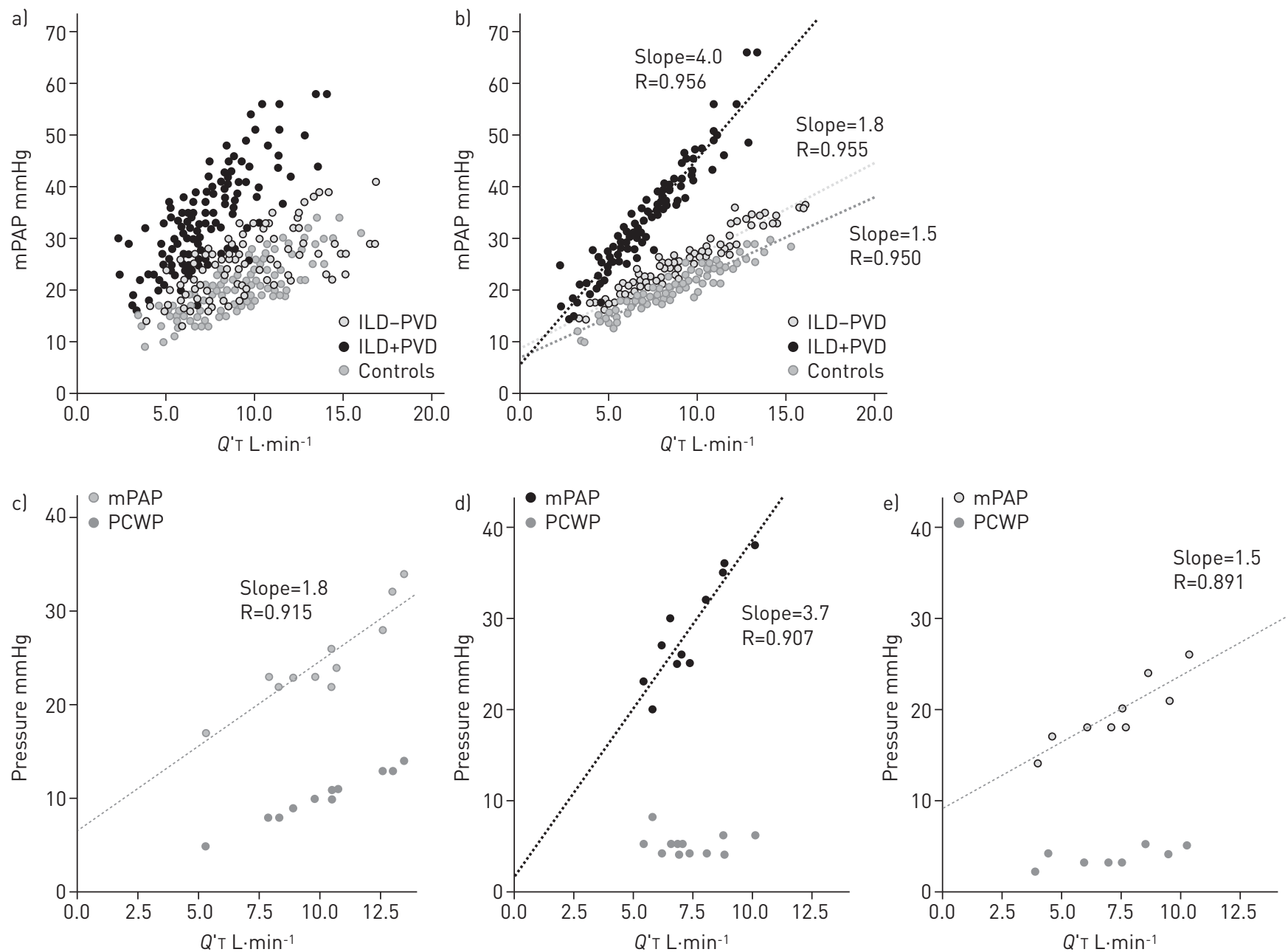

FIGURE 1 Pressure-flow relationships in interstitial lung disease (ILD) plus or minus pulmonary vascular dysfunction (PVD) and controls. a) Minute-by-minute mean pulmonary arterial pressure (mPAP) indexed to cardiac output $\left(Q^{\prime} T\right)$ in all subjects. b) Poon linear fit of the data points yielded similar slopes in each group. Minute-by-minute mPAP and pulmonary capillary wedge pressure (PCWP) indexed to $Q^{\prime} \mathrm{T}$ in representative subjects of each group: c) controls; d) ILD+PVD; e) ILD-PVD.

FIGURE 2 Relationship between peak pulmonary vascular resistance (PVR) and mean pulmonary arterial pressure (mPAP)-cardiac output $\left(Q^{\prime} \mathrm{T}\right)$ slope.

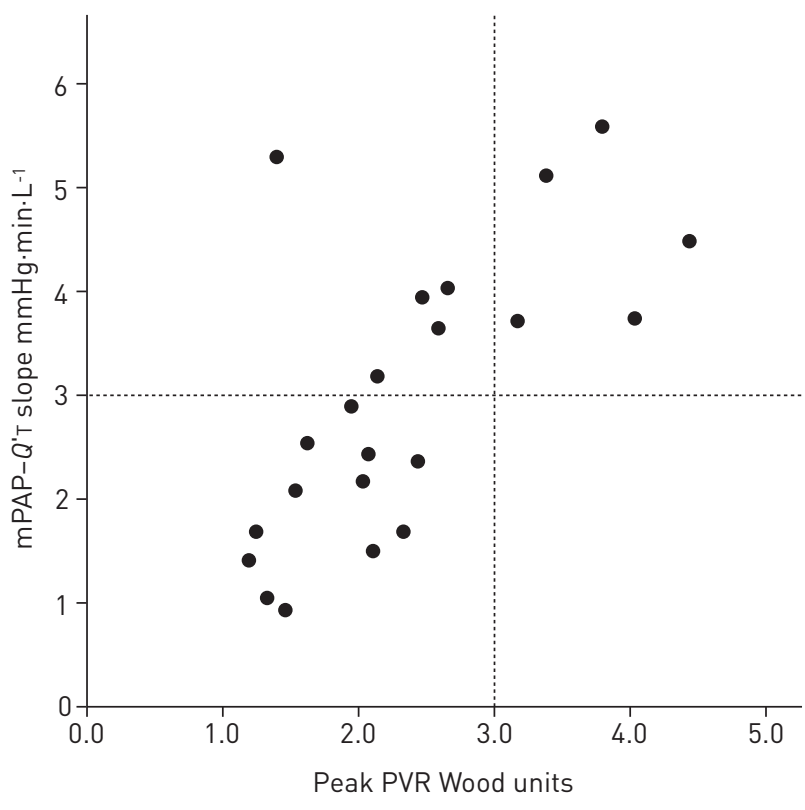




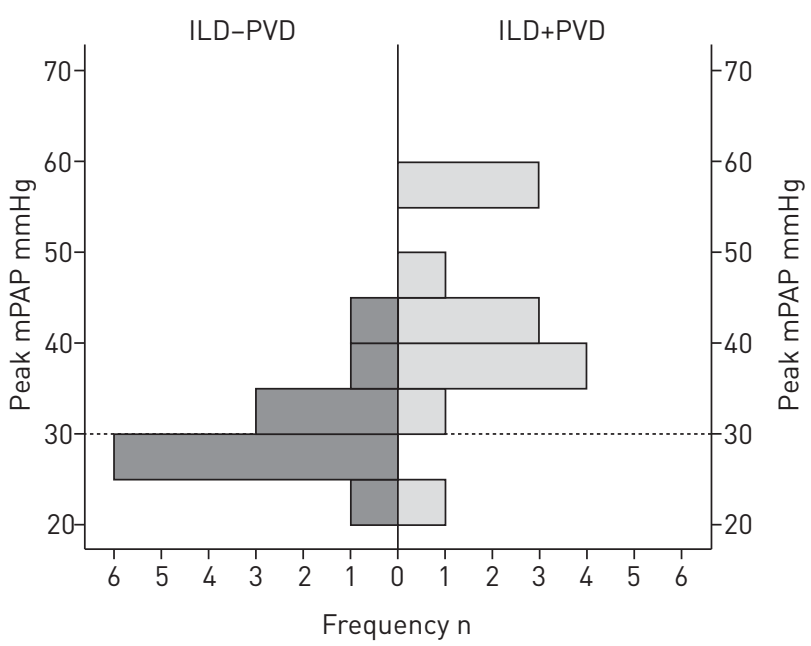

FIGURE 3 Mean pulmonary arterial pressure (mPAP) at peak exercise in interstitial lung disease (ILD) patients plus or minus abnormal pulmonary vascular response to exercise based on the mean pulmonary arterial pressure (mPAP)cardiac output slope definition of exercise-induced pulmonary hypertension.

$13 \pm 1 \mathrm{~mL} \cdot \mathrm{kg}^{-1} \cdot \mathrm{min}^{-1}$ compared to $17 \pm 1 \mathrm{~mL} \cdot \mathrm{kg}^{-1} \cdot \mathrm{min}^{-1}$ in the ILD-PVD group ( $\mathrm{p}=0.012$ ) (table 4). $\%$ predicted peak $V^{\prime} \mathrm{O}_{2}$ was also lower in ILD+PVD patients and, even though this difference did not reach statistical significance, there was a negative correlation between $\mathrm{mPAP}-Q^{\prime} \mathrm{T}$ slope and $\%$ predicted peak $V^{\prime} \mathrm{O}_{2}(\mathrm{R}=-0.444, \mathrm{p}=0.023)$ in our study sample. Moreover, stroke volume, $Q^{\prime} \mathrm{T}$ and cardiac index at peak exercise were lower in ILD+PVD than in ILD-PVD, and it is interesting to note that the differences seen in $V^{\prime} \mathrm{O}_{2}$ at the anaerobic threshold and peak exercise were proportional to the between-group differences in stroke volume, $Q^{\prime} T$ and cardiac index (table 4). As expected, the ILD+PVD group had higher mPAP and PVR at peak exercise $(\mathrm{p}<0.05)$. The peak PCWP, however, did not differ between the ILD-PVD and ILD+PVD groups, and tended to remain normal in the patient population studied, with only three subjects exceeding $18 \mathrm{mmHg}$ during exercise, which points to the predominantly pre-capillary mechanism of the hypertensive pulmonary vascular response to exercise in our sample (figs 1c-e and $4 a-c$ ).

ILD+PVD subjects showed increased dead space ventilation as evidenced by the higher dead space volume $(V D) /$ tidal volume $(V T)$ both at rest and peak exercise. Higher fractional dead space resulted in more

TABLE 3 Baseline characteristics of interstitial lung disease (ILD) patients plus or minus pulmonary vascular dysfunction (PVD)

\begin{tabular}{|c|c|c|c|}
\hline & ILD+PVD & ILD-PVD & p-value \\
\hline Patients $\mathbf{n}$ & 15 & 12 & \\
\hline Age years & $68 \pm 3$ & $61 \pm 3$ & 0.147 \\
\hline Female \% & 53 & 50 & 0.863 \\
\hline UIP n & 9 & 8 & 0.653 \\
\hline BMI $\mathrm{kg} \cdot \mathrm{m}^{-2}$ & $27.5 \pm 1.3$ & $26.1 \pm 1.3$ & 0.456 \\
\hline Positive smoking history $\%$ & 73.3 & 41.7 & 0.096 \\
\hline Smoking history pack-years & $37 \pm 16$ & $31 \pm 13$ & 0.779 \\
\hline FVC $\%$ predicted & $70 \pm 3$ & $66 \pm 6$ & 0.573 \\
\hline TLC $\%$ predicted & $72 \pm 4$ & $64 \pm 6$ & 0.261 \\
\hline DLCO ${ }_{\mathrm{Hb}} \%$ predicted & $40 \pm 3$ & $46 \pm 6$ & 0.392 \\
\hline $\mathrm{PaO}_{2} \mathrm{mmHg}$ & $81 \pm 4$ & $82 \pm 3$ & 0.877 \\
\hline $\mathrm{SO}_{2} \%$ & $96 \pm 1$ & $96 \pm 1$ & 0.380 \\
\hline GGO $n$ & 10 & 4 & 0.213 \\
\hline Reticulation $\mathbf{n}$ & 12 & 10 & 0.912 \\
\hline Honeycombing $\mathbf{n}$ & 8 & 6 & 0.978 \\
\hline Bronchiectasis $\mathrm{n}$ & 10 & 10 & 0.476 \\
\hline
\end{tabular}

Data are presented as mean \pm SEM, unless otherwise stated. UIP: usual interstitial pneumonia; BMI: body mass index; FVC: forced vital capacity; TLC: total lung capacity; $D \mathrm{LCO}_{\mathrm{Hь}}$ : diffusing capacity of the lung for carbon monoxide corrected for haemoglobin; $\mathrm{PaO}_{2}$ : arterial oxygen tension; $\mathrm{SO}_{2}$ : oxygen saturation; $\mathrm{GGO}$ : ground-glass opacity. 
TABLE 4 Cardiopulmonary exercise testing parameters in interstitial lung disease (ILD) patients plus or minus pulmonary vascular dysfunction (PVD)

\begin{tabular}{|c|c|c|c|c|c|c|}
\hline & \multicolumn{2}{|c|}{ ILD+PVD" } & \multicolumn{2}{|c|}{ ILD-PVD" } & \multicolumn{2}{|r|}{ p-value } \\
\hline & Rest & Peak exercise & Rest & Peak exercise & Rest & Peak exercise \\
\hline $\begin{array}{l}\text { mPAP-Q'T slope } \\
\mathrm{mmHg} \cdot \min \cdot \mathrm{L}^{-1}\end{array}$ & & $4.1 \pm 0.3$ & & $1.9 \pm 0.2$ & & $<0.001$ \\
\hline Maximum workload W & & $75 \pm 9$ & & $94 \pm 12$ & & 0.223 \\
\hline$V^{\prime} \mathrm{O}_{2}$ at $\mathrm{AT} \%$ & & $30 \pm 2$ & & $38 \pm 2$ & & 0.025 \\
\hline $\begin{array}{l}\text { Peak } V^{\prime} \mathrm{O}_{2} \\
\mathrm{~mL} \cdot \mathrm{kg}^{-1} \cdot \min ^{-1}\end{array}$ & & $13 \pm 1$ & & $17 \pm 1$ & & 0.012 \\
\hline Peak $V^{\prime} \mathrm{O}_{2} \%$ predicted & & $56 \pm 2$ & & $66 \pm 5$ & & 0.075 \\
\hline$Q^{\prime}$ T L·min $\min ^{-1}$ & $4.5 \pm 0.4$ & $9.3 \pm 0.6$ & $5.4 \pm 0.3$ & $12.5 \pm 0.8$ & 0.103 & 0.006 \\
\hline $\mathrm{CI} L \cdot \min ^{-1} \cdot \mathrm{m}^{-2}$ & $2.4 \pm 0.2$ & $4.9 \pm 0.3$ & $2.9 \pm 0.2$ & $6.6 \pm 0.3$ & 0.082 & 0.001 \\
\hline SV mL & $59 \pm 4$ & $73 \pm 5$ & $73 \pm 6$ & $96 \pm 6$ & 0.057 & 0.007 \\
\hline HR beats $\cdot \min ^{-1}$ & $78 \pm 4$ & $131 \pm 7$ & $75 \pm 3$ & $132 \pm 5$ & 0.575 & 0.912 \\
\hline $\mathrm{O}_{2}$ pulse & & $7.9 \pm 0.6$ & & $9.7 \pm 0.7$ & & 0.078 \\
\hline mPAP mmHg & $23 \pm 1$ & $43 \pm 3$ & $17 \pm 1$ & $31 \pm 2$ & 0.001 & 0.001 \\
\hline $\mathrm{mPCWP} \mathrm{mmHg}$ & $7 \pm 1$ & $13 \pm 3$ & $4 \pm 1$ & $9 \pm 1$ & 0.015 & 0.252 \\
\hline PVR Wood units & & $3.2 \pm 0.4$ & & $1.8 \pm 0.1$ & & 0.001 \\
\hline$V^{\prime} E_{\max } / M V V \%$ & & $84 \pm 5$ & & $83 \pm 6$ & & 0.952 \\
\hline V $/ V$ 个 $\%$ & $41 \pm 2$ & $39 \pm 2$ & $34 \pm 2$ & $30 \pm 2$ & 0.035 & 0.008 \\
\hline$V^{\prime} \mathrm{E} / V^{\prime} \mathrm{CO}_{2}$ at $\mathrm{AT}$ & & $45 \pm 2$ & & $38 \pm 1$ & & 0.015 \\
\hline $\mathrm{PETCO}_{2}$ at AT & & $31 \pm 1$ & & $35 \pm 1$ & & 0.085 \\
\hline $\mathrm{SO}_{2} \%$ & $96 \pm 1$ & $89 \pm 2$ & $96 \pm 1$ & $89 \pm 2$ & & 0.820 \\
\hline $\mathrm{PaO}_{2} \mathrm{mmHg}$ & $81 \pm 4$ & $62 \pm 5$ & $82 \pm 3$ & $63 \pm 5$ & & 0.906 \\
\hline 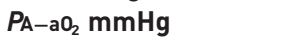 & & $61 \pm 8$ & & $50 \pm 5$ & & 0.287 \\
\hline
\end{tabular}

Data are presented as mean \pm SEM, unless otherwise stated. mPAP: mean pulmonary arterial pressure; $Q^{\prime} T$ : cardiac output; $V^{\prime} \mathrm{O}_{2}$ : oxygen consumption; $\mathrm{AT}$ : anaerobic threshold; $\mathrm{Cl}$ : cardiac index; SV: stroke volume; HR: heart rate; MPCWP: mean pulmonary capillary wedge pressure; $V^{\prime} E_{\max }$ : maximum minute ventilation at peak exercise; MVV: maximum voluntary ventilation; $V_{D}$ : dead space volume; $V_{T}$ : tidal volume; $V^{\prime} E$ : minute ventilation; $V^{\prime} \mathrm{CO}_{2}$ : carbon dioxide production; $\mathrm{PETCO}_{2}$ : end-tidal carbon dioxide tension; $\mathrm{SO}_{2}$ : oxygen saturation; $\mathrm{PaO}_{2}$ : arterial oxygen tension; $\mathrm{PA}_{\mathrm{A}-\mathrm{aO}}$ : alveolar-arterial oxygen tension difference. ${ }^{\#}: \mathrm{n}=15 ;{ }^{\text {" }}$ $\mathrm{n}=12$. Bold indicates statistical significance.

inefficient ventilation (i.e. higher minute ventilation $\left(V^{\prime} \mathrm{E}\right) /$ carbon dioxide production $\left(V^{\prime} \mathrm{CO}_{2}\right)$ at the anaerobic threshold) in ILD+PVD (fig. $4 \mathrm{~d}$ and e). However, the ventilatory inefficiency and haemodynamic impairment did not impact on the magnitude of oxygen desaturation in ILD+PVD patients, as both ILD+PVD and ILD-PVD showed an average drop of 7 units in $\mathrm{SO}_{2}$ from rest to peak exercise and reached a mean value of $89 \%$ at the end of the test.

Classification of Ei-PH by mPAP $\geqslant 30$ or $<30 \mathrm{mmHg}$ does not result in between group differences in peak $Q^{\prime} \mathrm{T}$, peak cardiac index, $V^{\prime} \mathrm{E} / V^{\prime} \mathrm{CO}_{2}$ at the anaerobic threshold or peak $V \mathrm{D} / V \mathrm{~T}$.

\section{Discussion}

In the present study, we found a $24 \%$ prevalence of pulmonary hypertension at rest $(n=7)$, as well as an additional 28\% $(n=8)$ prevalence of abnormal pulmonary vascular response patterns during exercise based on a $\mathrm{mPAP}-\mathrm{Q}^{\prime} \mathrm{T}$ slope $\geqslant 3 \mathrm{mmHg} \cdot \mathrm{min} \cdot \mathrm{L}^{-1}$ at peak exercise. By integrating pathophysiological responses to exercise into assessment of the pulmonary vasculature in ILD, we reclassified $28 \%$ of the patients by defining an Ei-PH phenotype. Despite similar demographic variables, PFT and radiographic results, the ILD+PVD group demonstrated impairment in several measurements associated with functional capacity and prognosis in pulmonary hypertension, including $V^{\prime} \mathrm{O}_{2}$ at the anaerobic threshold, peak $V^{\prime} \mathrm{O}_{2}$ and $V^{\prime} \mathrm{E} / V^{\prime} \mathrm{CO}_{2}$ at the anaerobic threshold. These findings suggest that PAP responses to exercise may help to refine resting phenotypes related to pulmonary vascular dysfunction in ILD.

\section{Pulmonary hypertension in the setting of ILD}

In a recent cohort of 212 subjects with ILD of mixed aetiologies (IPF, NSIP, sarcoidosis, hypersensitivity pneumonitis and CTD-related ILD), the prevalence of pulmonary hypertension was $14 \%$, where pulmonary hypertension was defined by systolic pulmonary arterial pressure (SPAP) $>40 \mathrm{mmHg}$ and tricuspid annular plane systolic excursion $<1.8$ or a dilated right ventricle on a resting echocardiogram [18]. We believe that the difference in the prevalence of resting pulmonary hypertension between our 

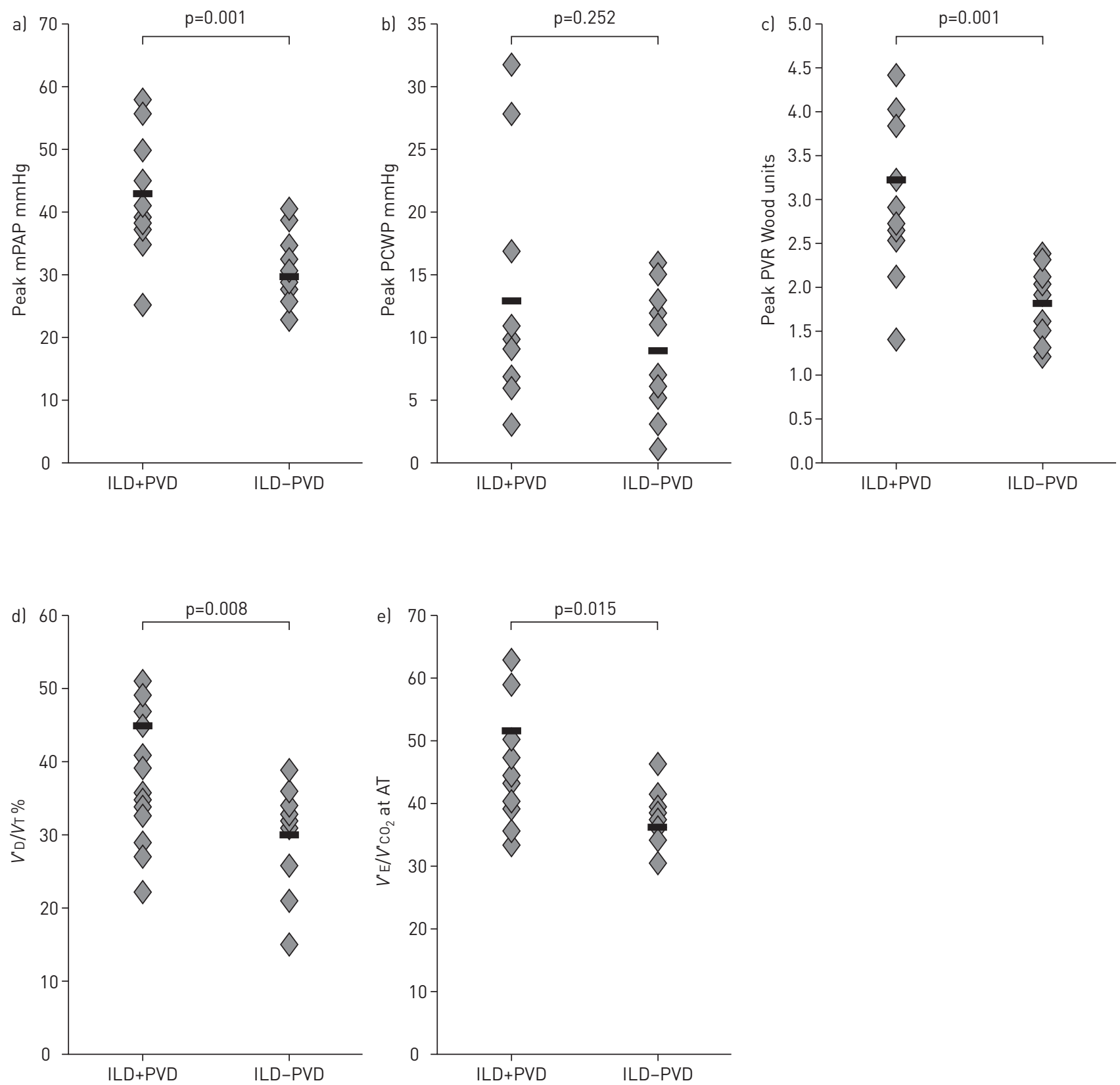

FIGURE 4 Exercise parameters in interstitial lung disease (ILD) plus or minus pulmonary vascular dysfunction (PVD). a) Mean pulmonary arterial pressure $(\mathrm{mPAP})$. b) Pulmonary capillary wedge pressure (PCWP). c) Pulmonary vascular resistance (PVR). d) Dead space ventilation $\left(V^{\prime} \mathrm{D}\right) /$ tidal volume (VT). e) Minute ventilation $\left(V^{\prime} \mathrm{E}\right) /$ carbon dioxide production $\left(V^{\prime} \mathrm{CO}_{2}\right)$ at the anaerobic threshold $(\mathrm{AT})$.

study and that of ANDERSEN et al. [18] could be at least partially attributed to a reduced sensitivity of the echocardiographic criteria for pulmonary hypertension diagnosis. However, the high prevalence of pulmonary hypertension in our study could have resulted from a potential selection bias, since the most symptomatic patients are the ones who tend to be sent for iCPET.

Previous studies have been able to show a relationship between reduced DLCO and increased prevalence of pulmonary hypertension in patients with ILD [10, 18-20]. In the present study, even though mean group DLCO was lower in ILD+PVD compared with ILD-PVD, this difference was not statistically significant. In line with previous reports $[19,21]$, the presence of pulmonary hypertension did not correlate with the severity of the restrictive ventilatory defect or the degree of desaturation on exertion. Age, sex, BMI and radiographic findings were also similar between ILD+PVD and ILD-PVD.

Finally, even though it has been previously suggested that patients with UIP are at higher risk of developing pulmonary hypertension [18], in our study, subjects with UIP were equally distributed between 
the groups. In addition, because PVD is known to arise with CTD and sarcoidosis, we examined whether the seven subjects with CTD had a differential mPAP- $Q^{\prime} T$ response pattern. No differences were observed between ILD patients with and without CTD $\left(3.1 \pm 0.6\right.$ versus $2.8 \pm 0.3 \mathrm{mmHg} \cdot \mathrm{L} \cdot \mathrm{min}^{-1}$, respectively; $\left.\mathrm{p}=0.62\right)$

\section{CPET in ILD}

A number of studies have demonstrated that ILD patients with overt pulmonary hypertension have poorer aerobic capacity and gas exchange than those without pulmonary hypertension. In the study by BouTOU et al. [1], SPAP correlated with peak $V^{\prime} \mathrm{O}_{2}$, anaerobic threshold, peak oxygen pulse, end-tidal carbon dioxide tension $\left(\mathrm{PTCO}_{2}\right)$ at the anaerobic threshold and during peak exercise, as well as $V^{\prime} \mathrm{E} / V^{\prime} \mathrm{CO}_{2}$ at the anaerobic threshold, but only the latter was able to independently predict the presence of pulmonary hypertension. ARmStrong et al. [19] showed that ILD subjects with pulmonary hypertension $(\mathrm{n}=25)$ have higher $V^{\prime} \mathrm{E} / V^{\prime} \mathrm{CO}_{2}$ as well as lower expiratory carbon dioxide tension and $P \mathrm{ETCO}_{2}$, both at the anaerobic threshold and during peak exercise, compared with ILD patients without pulmonary vascular disease $(n=50)$. The fact that between-group difference in $V D / V T$ was not statistically significant was considered to be further evidence that the worse gas exchange pattern in ILD+PVD resulted mainly from perfusion abnormalities.

In our study, the presence of abnormal pulmonary vascular responses to exercise was associated with increased peak $V \mathrm{D} / V \mathrm{~T}$ and $V^{\prime} \mathrm{E} / V^{\prime} \mathrm{CO}_{2}$ at the anaerobic threshold, and translated into poorer aerobic capacity (earlier anaerobic threshold, lower peak $V^{\prime} \mathrm{O}_{2}$ and maximum workload) in the ILD+PVD group compared to ILD-PVD group and controls. There was also a trend towards lower $\mathrm{ETCO}_{2}$ at anaerobic threshold in the ILD+PVD group. The trend towards lower $\mathrm{PETCO}_{2}$ in ILD+PVD and the fact that both groups had similar impairment in lung function speaks in favour of the differences in gas exchange being driven by the pulmonary vascular disease in the group ILD+PVD.

\section{iCPET to define abnormal pulmonary vascular responses to exercise}

Since $\mathrm{mPAP}=\mathrm{PVR} \times \mathrm{Q}^{\prime} \mathrm{T}+\mathrm{mPCWP}$, it is clear that the absolute value of mPAP at peak exercise depends not only on the ability to appropriately decrease PVR by mechanisms of pulmonary vascular recruitment and distensibility but also on the peak $Q^{\prime} T$ and the presence or absence of left heart disease. Therefore, establishing a rigid cut-off for the absolute value of $\mathrm{mPAP}$ ignores the impact of the increased $Q^{\prime} \mathrm{T}$ and leads to a high percentage of false-positive results, one of the reasons why the definition of pulmonary hypertension based on mPAP $>30 \mathrm{mmHg}$ during exercise was eventually removed from the pulmonary hypertension guidelines [22]. This observation is further confirmed in our study by the fact that $42 \%$ of the patients in the ILD-PVD group and $36 \%$ of control subjects would have been considered to have Ei-PH had we adopted this definition. These control patients reached mPAP values $>30 \mathrm{mmHg}$ on account of increased $Q^{\prime} T$ and not because of abnormally high left atrial pressure (LAP) or PVR.

Ideally, assessment of exercise-induced increases in mPAP should be interpreted relative to increases in $Q^{\prime} \mathrm{T}[2,3,23]$. The ability of the pulmonary vasculature to distend in response to increased $Q^{\prime} \mathrm{T}$ appears to be higher in women than in men and decreases with age [24], but the limits of normal of mPAP-Q'T relationships range from 0.5 to $3.0 \mathrm{mmHg} \cdot \mathrm{min} \cdot \mathrm{L}^{-1}$, as defined in heterogeneous populations. Therefore, a $\mathrm{mPAP}-\mathrm{Q}^{\prime} \mathrm{T}$ slope $\geqslant 3 \mathrm{mmHg} \cdot \mathrm{min} \cdot \mathrm{L}^{-1}$ appears to be a reasonable cut-off for the diagnosis of Ei-PH [23]. Central pulmonary pressures have been traditionally measured at end-expiration on resting right heart catheterisation under the argument that at functional residual capacity, the impact of pleural pressure on the value of pulmonary pressures would be minimised [25]. However, it has been recently shown that large intrathoracic pressure swings during exercise may result in overestimation of central pulmonary pressures in COPD patients when measurements are taken at end-expiration [26] and potentially opposite effects in ILD; therefore, we used an average over the breathing cycle in this study. Another distinct advantage of looking at change in PAP versus change in flow is that it renders the zero level irrelevant. Similarly, differences in where PAP is measured in the respiratory cycle compared to an absolute value cut-point are no longer a concern.

The mPAP-Q'T slope integrates LAP and PVR throughout exercise, which fails to fall appropriately and remains elevated at peak exercise in patients with pulmonary vascular disease. For that reason, some authors have suggested using PVR $>3$ Wood units at peak exercise as an indicator of Ei-PH [27]. It is interesting to note, however, that applying this definition in our study population would have led to five patients being categorised as having normal pulmonary vascular response to exercise. Therefore, this reinforces the notion that the use of a single haemodynamic variable, such mPAP or PVR, may be inadequate to define a normal versus abnormal pulmonary vascular response to exercise [28]. Further long-term outcomes studies are needed to evaluate the prognostic significance and natural history of abnormal pulmonary vascular responses to exercise in ILD. 


\section{Limitations}

Assessment of mPAP-Q'T slope with iCPET in identifying pulmonary vascular disease has some limitations. First, it depends on the patient exercising for long enough to generate a reliable slope ( preferably four or more measurements of PAP and $Q^{\prime} T$ ). Second, a mPAP- $Q^{\prime} \mathrm{T}$ slope $\geqslant 3 \mathrm{mmHg} \cdot \mathrm{min} \cdot \mathrm{L}^{-1}$, by itself, does not differentiate patients with exercise-induced pre-capillary $\mathrm{PH}$ from those with a predominantly post-capillary pressure elevation. We therefore performed PCWP measurements to quantify pre- and post-capillary components of the $\mathrm{mPAP}-\mathrm{Q}^{\prime} \mathrm{T}$ response to exercise. When analysing the pattern of pulmonary vascular response in the ILD+PVD group according to the criteria proposed by SAGGAR et al. [29], there were five patients with a pre-capillary pattern (peak PCWP $\leqslant 18 \mathrm{mmHg} \mathrm{mPAP}-Q^{\prime} \mathrm{T}$ and transpulmonary gradient (TPG) $\geqslant 15 \mathrm{mmHg}$ at peak exercise), one with a passive post-capillary pattern (peak PCWP $>18 \mathrm{mmHg}$ and TPG $<15 \mathrm{mmHg}$ at peak exercise) and two who developed exercise out-of-proportion pulmonary hypertension (PCWP $>18 \mathrm{mmHg}$ and TPG $\geqslant 15 \mathrm{mmHg}$ at peak exercise). While this classification remains under debate, it provides insight on the mechanisms behind the development of abnormal pulmonary vascular responses to exercise in patients with ILD.

Other limitations relate to the small sample size and, consequently, the reduced study power, which increases the chance of incurring on a Type II error in comparisons of ILD+PVD and ILD-PVD groups. Second, our subjects had surprisingly mild restrictive ventilatory defect compared with patients in previous studies in ILD where differences in CPET parameters between patients with and without pulmonary hypertension were investigated. Therefore, it is possible that, had our subjects shown more severe pulmonary function impairment, non-invasive CPET parameters could have been able to predict the presence of pulmonary vascular disease. In patients with advanced ILD, iCPET may not be able to be performed due to disease severity and the need for supplemental oxygen. Therefore, advanced ILD, in which PVD is likely to be even more prevalent, was underrepresented in our study. Finally, we cannot affirm, based on our data, that the radiographic severity of the ILD is or is not associated with the presence of pulmonary hypertension or exercise PVD because of the lack of a standard method to quantify radiographic abnormalities led to a simple categorisation of these variables into present or absent.

\section{Conclusions}

In ILD, a mPAP-Q $Q^{\prime} \mathrm{T}$ slope $\geqslant 3 \mathrm{mmHg} \cdot \mathrm{min} \cdot \mathrm{L}^{-1}$ is associated with lower peak $V^{\prime} \mathrm{O}_{2}$ and $Q^{\prime} \mathrm{T}$, as well as increased dead space ventilation and inefficient ventilation during exercise. While noninvasive parameters, such as PFTs and oxygen desaturation pattern, were unable to predict those with abnormal pulmonary vascular responses to exercise, use of iCPET to derive mPAP-Q' $T$ slope may aid in unmasking physiologically significant early pulmonary vascular disease in ILD. Further studies are needed in order to identify potential subgroups of ILD patients who could benefit from invasive assessment of pulmonary haemodynamics during exercise as well as to determine whether treatment of ILD-PVD with $\mathrm{PAH}$-directed therapies will improve functional capacity and prognosis in this patient population.

\section{References}

1 Boutou AK, Pitsiou GG, Trigonis I, et al. Exercise capacity in idiopathic pulmonary fibrosis: the effect of pulmonary hypertension. Respirology 2011; 16: 451-458.

2 Naeije R, Vanderpool R, Dhakal BP, et al. Exercise-induced pulmonary hypertension. Am J Respir Crit Care Med 2013; 187: 576-583.

3 Lewis GD, Bossone E, Naeije R, et al. Pulmonary vascular hemodynamic response to exercise in cardiopulmonary diseases. Circulation 2013; 128: 1470-1479.

4 Lewis GD, Murphy RM, Shah RV, et al. Pulmonary vascular response patterns during exercise in left ventricular systolic dysfunction predict exercise capacity and outcomes. Circ Heart Fail 2011; 4: 276-285.

5 Tolle JJ, Waxman AB, Van Horn TL, et al. Exercise-induced pulmonary arterial hypertension. Circulation 2008; 118: 2183-2189.

6 Magne J, Lancellotti P, Pierard LA. Exercise pulmonary hypertension in asymptomatic degenerative mitral regurgitation. Circulation 2010; 122: 33-41.

7 Lancellotti P, Magne J, Donal E, et al. Determinants and prognostic significance of exercise pulmonary hypertension in asymptomatic severe aortic stenosis. Circulation 2012; 126: 851-859.

8 Kessler R, Faller M, Weitzenblum E, et al. "Natural history" of pulmonary hypertension in a series of 131 patients with chronic obstructive lung disease. Am J Respir Crit Care Med 2001; 164: 219-224.

9 Condliffe R, Kiely DG, Peacock AJ, et al. Connective tissue disease-associated pulmonary arterial hypertension in the modern treatment era. Am J Respir Crit Care Med 2009; 179: 151-157.

10 Lettieri CJ, Nathan SD, Barnett SD, et al. Prevalence and outcomes of pulmonary arterial hypertension in idiopathic pulmonary fibrosis. Chest 2006; 129: 746-752.

11 Nadrous HF, Pellikka PA, Krowka MJ, et al. Pulmonary hypertension in patients with idiopathic pulmonary fibrosis. Chest 2005; 128: 2393-2399.

12 Patel NM, Lederer DJ, Borczuk AC, et al. Pulmonary hypertension in idiopathic pulmonary fibrosis. Chest 2007; 132: 998-1006.

13 Kimura M, Taniguchi $\mathrm{H}$, Kondoh $\mathrm{T}$, et al. Pulmonary hypertension as a prognostic indicator at the initial evaluation in idiopathic pulmonary fibrosis. Respiration 2013; 85: 456-463. 
14 Launay D, Mouthon L, Hachulla E, et al. Prevalence and characteristics of moderate to severe pulmonary hypertension in systemic sclerosis with and without interstitial lung disease. J Rheumatol 2007; 34: 1005-1011.

15 Shorr AF, Helman DL, Davies DB, et al. Pulmonary hypertension in advanced sarcoidosis: epidemiology and clinical characteristics. Eur Respir J 2005; 25: 783-788.

16 Hoeper MM, Bogaard HJ, Condliffe R, et al. Definitions and diagnosis of pulmonary hypertension. J Am Coll Cardiol 2013; 62: D42-D50.

17 Poon CS. Analysis of linear and mildly nonlinear relationships using pooled subject data. J Appl Physiol 1988; 64: 854-859.

18 Andersen CU, Mellemkjaer S, Hilberg O, et al. Pulmonary hypertension in interstitial lung disease: prevalence, prognosis and 6 min walk test. Respir Med 2012; 106: 875-882.

19 Armstrong HF, Thirapatarapong W, Dussault NE, et al. Distinguishing pulmonary hypertension in interstitial lung disease by ventilation and perfusion defects measured by cardiopulmonary exercise testing. Respiration 2013; 86: 407-413.

20 Nadrous HF, Pellikka PA, Krowka MJ, et al. The impact of pulmonary hypertension on survival in patients with idiopathic pulmonary fibrosis. Chest 2005; 128: 616S-617S.

21 Caminati A, Cassandro R, Harari S. Pulmonary hypertension in chronic interstitial lung diseases. Eur Respir Rev 2013; 22: 292-301.

22 Badesh DB, Champion HC, Sanchez MAG, et al. Diagnosis and assessment of pulmonary arterial hypertension. J Am Coll Cardiol 2009; 54: S55-S66.

23 Lewis GD. Pulmonary vascular response patterns to exercise: is there a role for pulmonary arterial pressure assessment during exercise in the post-Dana era? Adv Pulm Hypertens 2010; 9: 92-100.

24 Argiento P, Vanderpool RR, Mule M, et al. Exercise stress echocardiography of the pulmonary circulation: limits of normal and sex differences. Chest 2012; 142: 1158-1165.

25 Champion HC, Michelakis ED, Hassoun PM. Comprehensive invasive and noninvasive approach to the right ventricle-pulmonary circulation unit: state of the art and clinical and research implications. Circulation 2009; 120: 992-1007.

26 Boerrigter $\mathrm{BG}$, Waxman $\mathrm{AB}$, Westerhof $\mathrm{N}$, et al. Measuring central pulmonary pressures during exercise in COPD: how to cope with respiratory effects. Eur Respir J 2014; 43: 1316-1325.

27 Gargani L, Pignone A, Agoston G, et al. Clinical and echocardiographic correlations of exercise-induced pulmonary hypertension in systemic sclerosis: a multicenter study. Am Heart J 2013; 165: 200-207.

28 Saggar R, Lewis GD, Systrom DM, et al. Pulmonary vascular responses to exercise: a haemodynamic observation. Eur Respir J 2012; 39: 231-234.

29 Saggar R, Khanna D, Furst DE, et al. Exercise-induce pulmonary hypertension associated with systemic sclerosis. Four distinct entities. Arthritis Rheum 2010; 62: 3741-3750. 